\title{
EXPLORING THE TYPES OF SMES WHICH COULD USE BLOGS AS A MARKETING TOOL: A PROPOSED FUTURE RESEARCH AGENDA
}

\author{
Adeline Chua \\ Department of Marketing \\ University of Otago, New Zealand \\ adeline.chua@otago.ac.nz \\ Ken Deans \\ Department of Marketing \\ University of Otago, New Zealand \\ ken.deans@otago.ac.nz \\ Craig M. Parker \\ School of Information Systems \\ Deakin University, Australia \\ craig.parker@deakin.edu.au
}

\begin{abstract}
Blogs appear to be gaining momentum as a marketing tool which can be used by organisations for such strategies and processes as branding, managing reputation, developing customer trust and loyalty, niche marketing, gathering marketing intelligence and promoting their online presence. There has been limited academic research in this area, and most significantly concerning the types of small and medium enterprises (SMEs) for which blogs might have potential as a marketing tool. In an attempt to address the knowledge gap, this paper presents a future research agenda (in the form of research questions) which can guide the eBusiness research community in conducting much needed studies in this area. This paper is particularly novel in that it aims to demonstrate how the heterogeneity of SMEs and their specific business uses of eBusiness technology such as blogs can form the central plank of a future research agenda. This is important because the existing eBusiness literature tends to treat eBusiness collectively rather than focusing on the specific business uses of different eBusiness technologies, and to treat SMEs as a homogeneous group. The paper concludes with a discussion of how this research agenda can form the basis of studies which use a range of different research methods, and how this "big picture" agenda approach might help the eBusiness research community build theory which better explains SME adoption and use of eBusiness.
\end{abstract}

Keywords Blogs, Web 2.0, Small and Medium Enterprises (SME), eBusiness, Marketing, Branding, Reputation Management, Trust, Internet 


\section{INTRODUCTION}

The new Internet (dubbed Web 2.0) has been hailed as the latest wave of technology which is customer-centric, progressive, user-generated, interactive and dynamic. Web 2.0 fosters community participation and builds on collective community intelligence in a formalised, dynamic information creation and sharing environment (O'Flaherty, 2008; Schroth \& Janner, 2007; Singh et al., 2008). Blogs are one such Web 2.0 tool (Schmidt, 2007; Singh et al., 2008) which a person (a blogger) can post entries containing commentaries, descriptions of events and other information (usually displayed in reverse date-time order), and readers can post comments immediately on these entries (including comments on other comments). The growth of blogs among individual Internet users over the years has been exponential. Technorati (2008) in August reports 133 million blogs indexed since 2002, while Universal McCann (2008) in March records 184 million worldwide. Whilst the numbers vary, it appears that blogging is widespread and here to stay.

However, blogs are no longer restricted to individual Internet users as a means of narrating their experiences and pithy observations. With technology advancing at an ever increasing rate, blogs are creating significant interest and excitement around the possibilities and opportunities for business. Despite this potential, the majority of literature available which reports on the use of blogs in business is predominantly practitioner articles, which highlights the current dearth of academic blog research. Further compounding this problem is that academic journal publication timelines move at a slower pace than the evolution of blogging. This paper helps address this issue by presenting a future research agenda on blogging in a business context for the eBusiness research community.

Most of the literature available on blog use in a business context focuses on large corporations, with little academic research studying blog use by Small and Medium Enterprises (SMEs) or the reasons why SMEs are not using blogs. Research on blog use by SMEs has only recently emerged and concentrates on how small businesses with limited budgets can use blogs as part of their online marketing (Harris et al., 2008), in project-based knowledge management systems (Ahn et al., 2007; Judge, 2007), or as a learning and training tool (Ahonen \& Syvänen, 2007; Hamburg, 2008; Hamburg \& Hall, 2008). Given the infancy of SME research concerning blogging, it is important for the eBusiness research community to have a clear future research agenda which provides research questions (which can also be turned into research propositions or hypotheses) to stimulate research in this area.

In this paper we develop this future research agenda on SME blogging by synthesising the (primarily) practitioner literature on blogs in large business and the more general literature on eBusiness adoption by SMEs. We decided to focus the research agenda on the potential of blogs to improve SME marketing strategies and processes for a couple of reasons:

- Blogs are primarily being used by businesses today as a marketing channel or to support marketing strategies and processes such as branding (Brooks, 2006; Dwyer, 2007), managing reputation and trust (Gordon, 2006; Gray, 2006; Singh et al., 2008), niche marketing (Singh et al., 2008), and gathering market intelligence (Habermann, 2005; O'Flaherty, 2008; Scoble \& Israel, 2006; Singh et al., 2008); and

- Parker and Castleman (2007) state that much of the existing research on SMEs and eBusiness investigate the adoption of the Internet, Web and eCommerce (or eBusiness) collectively. This collective approach fails to recognise that SMEs can use a platform such as the Web for various business applications such as for sales, payments, procurement, employee recruitment, online banking and online service delivery. We therefore thought that it was important to avoid examining SME adoption of "blogs", and instead examine the specific business applications 
(that is, those relating to marketing such as branding, gathering market intelligence) for which SMEs might be able to use blogs.

We felt that an equally important consideration when developing this future research agenda was to address the criticism that much of the existing eBusiness research tends to treat SMEs as a homogeneous group (see Castleman, 2004; Martin \& Matlay, 2001; Parker \& Castleman, 2007). This paper therefore does not take the technological expansionist view (after Castleman, 2004) that blogs are suitable for and should be adopted by "all" SMEs. Equally, we also want to avoid the opposite extreme which would be to assume that blogs are inappropriate for "any" SMEs because they are resource and time poor. Instead, if eBusiness researchers work with the future research agenda outlined in this paper they will (collectively at least) produce research findings which will result in a better understanding of the complex internal and external SME contexts governing whether or not the adoption of blogs makes sense for specific types of SMEs, and for specific purposes such as branding, intelligence gathering and so on. The significant conceptual contribution of this paper, therefore, is to demonstrate to the academic community how eBusiness research can be reconceptualised to ensure that SME heterogeneity, and the specific business applications of eBusiness technology, becomes central to the research questions we pursue.

Another benefit of a future research agenda is that it helps the academic community see where their projects fit within the "big picture" of research relating, in this case, to identifying the types of SMEs for which blogs have potential as a marketing tool. This is important because the eBusiness literature on SMEs is quite fragmented (Parker \& Castleman, 2007), and so having a "big picture" research agenda could provide a common reference point within which to integrate the literature. In addition, we anticipate that the agenda will increase the chances that a researcher's work will contribute to a fuller understanding of the phenomenon under study if there is a "big picture".

The paper is structured as follows. We first provide a brief overview of blogs and their emerging use in a business context, where existing examples predominantly relate to large corporations. We then examine briefly the dimensions of heterogeneity of SMEs, based on the broader eBusiness literature concerning SMEs, which might influence the blog adoption decisions of SME ownermanagers. Next we explore potential business applications of blogs within a marketing context and posit research questions relating to various marketing strategies and processes which take into account SME heterogeneity. We then discuss how these research questions, which comprise our proposed future research agenda, can be explored using various research methods. We also consider how this research agenda can contribute to theory building relating to SME adoption of eBusiness technologies such as blogs.

\section{THE RISE OF BLOGGING IN A BUSINESS CONTEXT}

A blog is a Web 2.0 tool in which a person (a blogger) posts entries which can contain commentaries, descriptions and other information, whereby each subsequent entry is displayed in reverse chronological order (Schmidt, 2007; Singh et al., 2008). Blogs are highly interactive because readers can post comments about a blog entry (and about comments posted by other readers), which in turn facilitates debates and dialogue between readers and the blogger. It is on this basis that blogs differ from online diaries and journals which, by contrast, can only be written and edited by the diary or journal author alone (Harris et al., 2008).

There is now growing evidence that blogs are being used by business as part of their customer relationship management strategies (Dwyer, 2007; Singh et al., 2008), which can include branding (Brooks, 2006; Dwyer, 2007), managing reputation and trust (Gordon, 2006; Gray, 2006; Singh et 
al., 2008), niche marketing (Singh et al., 2008), and gathering market intelligence (Habermann, 2005; O'Flaherty, 2008; Scoble \& Israel, 2006; Singh et al., 2008). Large organisations which have been successful in using blogs include Microsoft Corporation, The Walt Disney Company, CNBC, SUN Microsystems, General Motors, MTV Networks and Google (Carter, 2006; Holtz, 2005). Fortune 500 companies have also been found to be increasing their use of blogs since 2006 and into 2009 (Anderson \& Mayfield, 2009; Lee et al., 2006). In addition, a survey conducted by McKinsey in January 2007 of 2,847 executives found that blogs were ranked as the third most popular of the Web 2.0 tools which can be used for customer relationship management after social networking and podcasting (Bughin \& Manyika, 2007). Interestingly, the report also showed that there has been uptake of blogs among companies in Asia, Asia-Pacific and China, especially in retail and high technology industries (Bughin \& Manyika, 2007), which suggests that there is a growing interest in blogs (among other Web 2.0 tools) in other parts of the world besides USA and Europe. A growing awareness on the importance of blogs as a legitimate social media marketing tool is also substantiated by the increased amount of spending on blog-based promotion in 2005 (\$16.6 million) to an estimated \$300.4 million by 2010 (Singh et al., 2008).

With the growing evidence that blogs are being utilised by large organisations, it raises the question of what types of SMEs might benefit from blogs or be able to use them as a marketing tool. For example, what types of SMEs might find blogs easier to use for marketing than more traditional marketing approaches? Our examination of the practitioner and academic literature, however, suggests that this area has received little attention. Some notable exceptions included:

- A 2007 Forrester survey of 119 chief information officers (CIOs) working in SMEs and larger companies in the USA (Young et al., 2007), in which 89\% declared that they had adopted at least one Web 2.0 tool (out of blogs, wikis, podcasts, RSS, social networking and content tagging) and 35\% confirmed they were using them all. Although the authors did not distinguish between the SME and large business respondents, this study suggests that Web 2.0 tools such as blogs might already be in use by some SMEs (Young et al., 2007). The small sample size in the study does not make the findings generalisable, however these results should be seen as an indicative sign that blogs might be receiving recognition even by SMEs.

- Harris et al. (2008) conducted a telephone survey of 400 SMEs in the UK concerning their use of Web 2.0 tools, and 30 case studies of small firms which were "early adopters" of Web 2.0 tools including blogs. Their research only discussed the respondents' use of blogs very briefly, and did not explore the wide range of marketing strategies and processes of small businesses and how blogs might be used to support these marketing objectives.

- Singh et al. (2008) presents a general discussion of the marketing potential of blogs for businesses primarily focused on large firms, but they do include a couple of anecdotal examples of small businesses which have made effective use of blogs for marketing.

While this research is limited, what it does demonstrate is that some SMEs are making use of blogs as marketing tools, and this warrants additional research to explore the types of SMEs for which blogs might be applicable and useful. In order to fill this gap in knowledge we believe it is important to propose and outline a future research agenda which will guide eBusiness researchers in furthering our knowledge of the types of SMEs which could benefit from the use of blogs. 


\section{WHICH SME CHARACTERISTICS ARE SUITED TO BLOG USE?}

In order to establish a research agenda for determining the types of SMEs for which blogs might have potential as a marketing tool, we must ensure the heterogeneity of SMEs is taken into account (see Castleman, 2004; Martin \& Matlay, 2001; Parker \& Castleman, 2007). This is critical because previous eBusiness research on SMEs has tended to treat this sector as a homogeneous group rather than acknowledging that different eBusiness technologies and applications may suit (or not suit) disparate types of SMEs (Martin \& Matlay, 2001; Parker \& Castleman, 2007). A major objective of this future research, therefore, should be determining what characteristics of SMEs are most suited to using blogs for marketing. More specifically, we argue (after Castleman, 2004) that researchers who examine the potential for blogs (or any other eBusiness tool) in SMEs must avoid the technological expansionist view that their non-adoption of blogs is a failure of SMEs. Instead, we believe that blogs may only be suitable for a subset of SMEs, and that a future research agenda must provide guidance for determining this subset.

For this reason, we now outline the various dimensions on which SMEs are heterogeneous based on the broader eBusiness literature on SMEs, and use this literature to suggest the possible impact which each dimension might have on blog adoption by SMEs. It must be emphasised that future research will be required to determine whether, in fact, any of our suggestions hold true or not. For this reason, the overview we provide on the impact of SME heterogeneity on blog adoption and use will inform the next section of the paper in which we develop research questions to explore the types of SMEs for which blogs could be used to support their marketing strategies and processes.

The first area in which SMEs differ widely from one another is based on the owner-managers themselves. The characteristics or traits of SME owner-managers need to be considered, more so when compared to managers in large businesses, because the owner-manager is usually the principle decision-maker (Al-Qirim, 2005; Ching \& Ellis, 2004), while in large businesses decisions are more likely to be made collectively. Examples of the dimensions on which owner-managers can differ (and which might impact on blog adoption decisions and use) include:

- Their age and educational level (Burke, 2005; Ching \& Ellis, 2004; Fillis et al., 2004; Martin \& Matlay, 2001), which suggests that younger owner-managers and/or those more highly educated might be more likely to know about and consider blogs in their business.

- $\quad$ Their attitude toward eBusiness (Al-Qirim, 2005; Alexander et al., 2003; de Guinea et al., 2005; Del Aguila-Obra \& Padilla-Meléndez, 2006; Tsao et al., 2004) shaped by their knowledge of and experience with eBusiness (Al-Qirim, 2005; Del Aguila-Obra \& PadillaMeléndez, 2006; Dholakia \& Kshetri, 2004; Wymer \& Regan, 2005), which suggests that eBusiness savvy owner-managers might be more likely to use blogs and/or have a positive attitude toward them.

- $\quad$ Their degree of entrepreneurship, market (Ching \& Ellis, 2004; Galloway \& Mochrie, 2005; Jones et al., 2003; Simmons et al., 2008) and/or export orientation (Chong, 2006; Wagner et al., 2003). This eBusiness research suggests that owner-managers who are entrepreneurial, routinely scan their competitors, develop strategic plans, and so on might be more likely to preempt or respond to growing blog use in their industry by adopting blogs.

- Their business goals which vary from economic objectives such as competitive advantage and growth (Al-Qirim, 2005; Chong, 2006; MacGregor \& Vrazalic, 2007) to those who choose to keep their firm small to focus on family or their preference for lifestyle, enjoyment, socialising, autonomy, survival and stability (Castleman, 2004; Galloway \& Mochrie, 2005; Parker \& Castleman, 2007). This eBusiness research suggests that owner-managers with economically 
driven business goals might be more likely to see the value in and possibly use blogs if this tool is seen to help them achieve their business goals.

- Their degree of preference for face-to-face communication and associated trust with customers (and suppliers) as their primary competitive advantage over larger firms (Beck et al., 2005; Castleman, 2004; Zheng et al., 2004), whereby owner-managers might be less likely to use blogs if they perceive this tool will risk impersonalising or even damaging relationships.

The second area in which SMEs differ widely from one another is on the characteristics of the firm and its employees (assuming it has any). Examples of the dimensions on which SME organisations can differ (and which might impact on blog adoption decisions and use) include:

- $\quad$ The extent of employee eBusiness knowledge and skills (Al-Qirim, 2005; Beck et al., 2005; Caldeira \& Ward, 2003; Del Aguila-Obra \& Padilla-Meléndez, 2006; Jones et al., 2003; Stansfield \& Grant, 2003; Tucker \& Lafferty, 2004; Wymer \& Regan, 2005) and employee resistance to new changes or practices such as eBusiness (Beck et al., 2005; Tsao et al., 2004). This eBusiness research suggests that SMEs with eBusiness savvy employees might be more likely to have the skills to operate a blog, even if the owner-manager does not.

- The number of employees because as a firm grows its organisational structure and processes become more complex and results in job specialisation, formalisation, more coordination of business functions, etc (Burke, 2005; Levenburg, 2005). This suggests that larger SMEs are more likely to have staff with specialist skills in marketing and/or eBusiness, which might mean they would be more inclined to consider the value of blogs.

- The extent of marketing ability which exists within the SME, either by the owner-manager or employees (Simmons et al., 2008). This suggests that an SME with strong marketing ability might possess the internal capabilities which will ensure that the marketing potential of blogs is more likely to be understood and recognised.

The third area in which SMEs differ widely from one another is on the characteristics of the environment in which they operate. Examples of the dimensions on which the environment of SMEs can differ (and which might impact on blog adoption decisions and use) include:

- The extent of pressure from customers and/or suppliers to adopt and use eBusiness (Al-Qirim, 2005; Beck et al., 2005; Ching \& Ellis, 2004; Del Aguila-Obra \& Padilla-Meléndez, 2006; Gemino et al., 2006; Khazanchi, 2005; Stansfield \& Grant, 2003; Wymer \& Regan, 2005). In the context of blogs, this could relate to the extent of blog use by customers and whether they are pressuring SMEs to introduce blogs. Alternatively, the pressure could be indirect if customers are influenced by blogs (which could include reviews of an SME's products or services) when making purchase decisions.

- $\quad$ The extent and nature of eBusiness use within the industry (Khazanchi, 2005; Simmons et al., 2008; Xu et al., 2007). This suggests that blog use is likely to vary depending on the industry, the type of customers (as mentioned in the previous point) and the products/services.

- The extent to which SME owner-managers participate in and get their eBusiness adoption and general business advice via informal, often highly social, business networks (Beckinsale et al., 2006; Gibbs et al., 2007; MacGregor \& Vrazalic, 2007; Simmons et al., 2008) and/or get advice from family members (Galloway \& Mochrie, 2005; Martin \& Matlay, 2003; Simpson \& Docherty, 2004; Zheng et al., 2004). This suggests SME owner-managers who are members of personal or business networks might be inclined to follow the advice of opinion leaders in or the norms of these networks concerning blog use. If business use of blogs is high within the networks then other SME owner-managers might follow suit - the converse might apply too. 
- The extent to which SME owner-managers have good experiences with eBusiness solution providers, which is largely governed by the providers' eBusiness capability and knowledge (Martin \& Matlay, 2003) and the providers' understanding of the SME owner-manager's business goals and needs (Brown \& Lockett, 2004; Martin \& Matlay, 2003; Simpson \& Docherty, 2004). This suggests that it is the SME owner-managers who trust and value the advice of solution providers (if they are knowledgeable about the effective business use of blogs) who are more likely to use blogs in their business.

Of course, these dimensions are not mutually exclusive. For example, a sole operator who is eBusiness savvy and is selling services directly to young consumers might see value in establishing a blog if they want to be seen as "progressive". By contrast, a medium enterprise which has an IS department and specialises in manufacturing widgets for the mining sector might find blogs inappropriate if they do not perceive that their customer-base reads blogs. What the overview of SME heterogeneity emphasises is that when examining the potential of blogs it is important for eBusiness researchers to contextualise the circumstances of SMEs instead of assuming that there are universal adoption barriers and drivers which explain the eBusiness adoption behaviours of SMEs.

In the next section we explore the marketing strategies and processes which the (predominantly practitioner) literature suggests can be supported by blogs, and posit research questions to guide future research which will result in a better understanding of the SME contexts in which blogs will be most suitable.

\section{WHICH SME MARKETING STRATEGIES AND PROCESSES ARE SUITED TO BLOGS?}

Our earlier discussion of the apparent rise of blog use by business suggests that these tools have the potential to support a range of different marketing strategies and processes. Our analysis of the growing body of literature on blogs suggests that this potential might relate especially to branding (Brooks, 2006; Dwyer, 2007), managing reputation and trust (Gordon, 2006; Gray, 2006; Singh et al., 2008), niche marketing (Singh et al., 2008), gathering market intelligence (Habermann, 2005; O'Flaherty, 2008; Scoble \& Israel, 2006; Singh et al., 2008) and promoting an online presence (James, 2008). In the following sub-sections we examine each of these areas in more detail by describing how blogs can help with each of these marketing strategies or processes for businesses generally. More specifically we posit research questions which we believe will identify and produce insight into the types of SMEs who might be able to take advantage of blogs for each of these marketing strategies and processes.

\section{Branding}

Branding is an important marketing objective for organisations and can be achieved when they differentiate their products/services based on visual features (Arnold, 1992; Kotler et al., 1996) or offer a set of distinctive benefits or "promises" which meet the expectations of customers (Ambler, 1992; Walmsley, 2006). The relevance of branding for SMEs is not immediately apparent, because our previous discussion on heterogeneity suggests that not all SME owner-managers have the marketing ability, strategic plans or entrepreneurial orientations to develop and pursue a branding strategy. However, Castleman (2004) suggests that even if SME owner-managers are unable to articulate their brand in a traditional marketing sense, they might still have an innate sense of what makes their business new, unique or better than their competitors. For this reason, it is appropriate to consider whether blogs could be used by SMEs for a proactive (or indirect) branding strategy. 
Some advocates of blogging believe that this tool can support branding because it offers a "human" or interpersonal face to a brand which is more difficult to achieve using traditional advertising (Brooks, 2006; Dwyer, 2007) because they can be written by employees of the organisation including CEOs (van der Wolf, 2007). However, Walmsley (2006) argues that effective branding is not just about providing a "human face" to the product/service, but also ensuring that customers perceive products/services positively based on their experience, consumption and communication with the organisation. For this reason, Walmsley believes that blogs cannot support all aspects of branding. But blog advocates (eg, Brooks, 2006; Dwyer, 2007; Singh et al., 2008) argue that this tool should be seen as a component of customer retention in which organisations converse or communicate directly with existing customers to encourage a sense of connectedness with and produce positive experiences regarding the company. Woffington (2006) believes that it is this connectedness between customers and a company which helps develop brand loyalty because it gives customers a sense of ownership of the product/service.

Our previous heterogeneity discussion suggests that this benefit of blogs might be especially appealing to SME owner-managers who want to emphasise their interpersonal relationships with customers by blogging about their life, passion for their craft, and so on (see James, 2008). This raises the question of whether customers would respond better to blogs by SME owner-managers, or by employees, or both. Another type of SME who might benefit from blogs are those whose brand involves being at the forefront of technology, which means that participating in current trends like blogging might be critical to maintaining their eBusiness savvy image. Finally, entrepreneurial or growth oriented SMEs with owner-managers or employees who are skilled in public relations might be more inclined to see the potential of social media for promoting their brand (see Gray (2006) who describes how this is being achieved by large companies). This raises the following research questions which could be examined in future research: RQ1: What is the nature of SME branding strategies (whether planned by or the instinct
of the owner-manager) which are suited to blogging?
RQ2: What internal capabilities do SMEs need to use blogs to build brands effectively?
RQ3: Under what conditions might customers respond favourably to blogs written by SME employees rather than owner-managers?

RQ4: What customer demographics are conducive to blog-based contact, in preference to face-to-face, when SMEs develop interpersonal relationships?

RQ5: Which members of an SME owner-manager's personal and business networks will be most influential in governing their views of the branding potential of blogs?

RQ6: $\quad$ What are the characteristics of SME-dominated industries which are most suited to the use of blogs for branding?

\section{Managing reputation and trust}

A marketing objective related to branding is the need for small through to large organisations to manage their reputation and build associated trust with their customers. Blog advocates argue that this tool can be used to manage reputation and build trust by responding effectively and promptly to negative criticism and positive comments posted in blogs by customers (Gordon, 2006; Gray, 2006; Singh et al., 2008). These authors also believe that blogs can strengthen a company's relationships with customers by presenting the company in a more personal way to the public (Habermann, 2005). Blogs can also be used to collect, aggregate and distribute feedback between the company and its customers (Resnick et al., 2000). Many large organisations are recognising these various 
potentials of blogs and have started their own company blog for these purposes (Gordon, 2006; Habermann, 2005; Singh et al., 2008).

However, Hewitt (2005) argues that this is a high risk marketing strategy, which is probably why many marketers fear that there would be repercussions for their company's reputation if they created a blog and allowed customers to criticise publicly the company's products or advertising campaigns. This would be especially true of SMEs which would be more likely to be wary of placing their brand in new and fairly unpredictable media such as blogs (Deelmann \& Loos, 2002). Taylor (2005) points out, however, that a company's reputation can be at risk through third party blogs, not just those established by the company itself. For example, Kryptonite Corporation in the USA had a defect in their bike locks which they only discovered and verified when customers and traditional media picked up the story from third-party blogs and forum postings. This ultimately cost them their reputation (Taylor, 2005). Our previous SME heterogeneity discussion raises the question of what types of SMEs would have the resources to monitor third party blogs, or to establish their own blog, in order to detect and manage reputation risks from blogs.

Others have pointed out that the reputation of an organisation can also be damaged by unethical use of blogs (Carmichael \& Helwig, 2006; Cox et al., 2008), or using blogs purely as "marketing copy" (Cox et al., 2008). For example, Wal-Mart's reputation was tarnished when it was found that it fabricated a blog which was purportedly of a couple who were travelling in a recreational vehicle and camping for free in Wal-Mart parking lots, and who were blogging about their positive encounters with Wal-Mart employees (Carmichael \& Helwig, 2006). Such a deceptive and unethical practice places a company's reputation at risk (Cox et al., 2008). Similarly, Cox (2008) states that firms which use blogs to hype their products/services often find this ineffective as a marketing strategy because readers ignore "marketing copy”. This in turn reduces the company's reputation. Kirkpatrick et al. (2005, p. 47) agree, stating that “... corporate propaganda will always drive people away but only real people with real opinions will keep them coming back”. This suggests that SME owner-managers or staff need marketing know-how in order to avoid falling into the trap of using blogs as an advertising medium, instead of a customer relationship management tool.

Ultimately the impact of blogs on the reputation of an SME will depend on their context, such as whether their customer-base is a heavy user of blogs when making purchasing decisions, and whether online customer reviews are common in their industry. For example, those SMEs targeting teenagers or other market segments, whom we might expect to be frequent blog readers or contributors, might be at risk of losing their reputation if negative comments are posted on blogs and other online forums. And as with the previous discussion on branding, there is also the issue of whether SME owner-managers and staff have the marketing skills to take advantage of the reputation and trust building potential of blogs, and to avoid inappropriate uses of blogs which result in customer backlash. This raises the following research questions which can be examined in future research:

RQ7: What types of SMEs (based on their heterogeneous characteristics) are most at risk of having their reputation damaged by third party blogs?

RQ8: $\quad$ To what extent and under what circumstances do customers rely upon (third party or company-owned) blogs to decide whether or not to do business with SMEs?

RQ9: To what extent do SME owner-managers perceive that their company's reputation is at risk from online customer criticism in blogs (and other online forums)?

RQ10: What internal capabilities are needed by SMEs to operate a blog (for reputation management) and/or to monitor third-party blogs (and other online forums)? 


\section{Niche marketing}

SMEs are usually strong in conquering market niches (Nooteboom, 1994), which can be based on niche products/services or geographical niches such as rural communities (Martin \& Matlay, 2001). Blog advocates (eg, Singh et al., 2008) suggest that this tool can be used by organisations to develop vibrant communities of people who are interested in a niche area, because members of the community are empowered by blogs to converse on topics relating to their passion. Organisations can differentiate themselves by engaging with this community (via its own blog or that of a third party) to articulate viewpoints, knowledge and expertise (Sherman \& Weinberger, 2006; Wright, 2006) so that they are seen as leaders in their niche. Deelman and Loos (2002) suggest that online communities are one way in which SMEs can establish a reputation and build trust, which is an important component of niche marketing and differentiation, because community members tend to trust each other and this means that their positive feedback on an SME's products/services will therefore hold a lot of weight (see also DeFelice, 2006).

A New Zealand-registered company called Pinnacle Life is an example of an SME which has used a blog as part of its niche marketing strategy to build a community of people interested in life insurance. The company describes its target market as the younger, internet-savvy users, and its blog provides information about insurance issues in an attempt to inform the market and personalise the life insurance concept to its customer-base. Pinnacle Life has been successful in differentiating itself from competitors because it was the first company globally to offer a fully-automated "instant" life insurance via its online underwriting service. Customers need only answer a few questions online to receive a quotation and a direct comparison with other insurance companies within a few minutes. This has a number of advantages such as eliminating the need for third parties and complicated administrative layers, and passing the cost savings onto its customers. As a result Pinnacle Life won the US-based 2008 Innovator of the Year Award.

Our discussion here raises the interesting question of what types of SMEs could take advantage of the community building and niche marketing potential of blogs. The case of Pinnacle Life begs the question of what types of products/services traded by SMEs (or industries more broadly) lend themselves to the building of niche blog-based communities. Horton (2003) also warns that the ability to target a specific niche or community audience using blogs depends on whether the organisation has the internal skills and time to employ this approach successfully. Some possible research questions which can stimulate future research in this area include:

RQ11: What types of products/services lend themselves to the development of blog-based communities which can be used for niche marketing by SMEs?

RQ12: What internal capabilities are needed by SMEs to identify or develop a suitable blog-based community to support their niche strategy?

RQ13: What practical approaches can SMEs use (or tools be developed to assist them) to turn their product/service offerings into niche propositions which can be marketed via a blog-based community (given the limited resources of SMEs)?

RQ14: Which members of an SME owner-manager's personal and business networks will be most influential in governing their views of using blogs for niche marketing?

\section{Gathering market intelligence}

An important marketing process which can inform the marketing strategies of all organisations is the gathering of market intelligence. Blog advocates believe that the vibrant blog-based communities we described previously, and the dialogue occurring between customers and 
organisations, have the potential to help with this market research because blogs facilitate the ability of organisations to:

- gain market intelligence about the needs of customers (O'Flaherty, 2008; Scoble \& Israel, 2006)

- understand and track trends in their industry more efficiently than using traditional market research approaches (Habermann, 2005; Singh et al., 2008) (O'Flaherty, 2008; Scoble \& Israel, 2006)

- $\quad$ understand the decision-making processes of its customers (Cooke, 2006)

- gain insights into customers which can drive product developments (Singh et al., 2008; Woffington, 2006)

- gauge the market for new products/services (Hanson, 2006)

- $\quad$ gain insights into competitors (Habermann, 2005; Singh et al., 2008).

However, our discussion on the heterogeneity of SMEs would suggest that the use of blogs for market research by SMEs would be most likely limited to those with a strong marketing ability (either of the owner-manager or employees) and/or an entrepreneurial orientation. This is because these are the types of SMEs which might be more likely to recognise the importance of market research which is more traditionally undertaken by larger organisations with more resources (Zontanos \& Anderson, 2004). Some possible research questions which can stimulate future research into the potential of blogs for market research in the context of SMEs include:

RQ15: What are the characteristics of SMEs who are most likely to engage in market research and, therefore, to see the potential value of blogs?

RQ16: To what extent can blogs provide a practical mechanism by which SMEs can engage in market research given their limited resources?

RQ17: Can automated tools be developed which can assist SMEs to mine blog content to obtain cheap, effective market intelligence?

\section{Promoting an online presence}

Another marketing process challenge for organisations which do have an online presence is understanding how to increase the flow of traffic to their website, increase their online visibility (James, 2008) and hence increase sales. One way that organisations can achieve this goal is to improve its ranking in search engine results when prospective customers use these search engines to identify and research potential products/services. Some blog advocates (eg, Gordon, 2006; Habermann, 2005; O'Flaherty, 2008) claim that companies which frequently update their blogs and which have numerous links to their website from third party blogs and websites often rank higher in search engine results. This can even apply to SMEs because, for example, a small sheet UK metal fabrication plant called Butler Sheet Metal used a blog to boost its profile by posting honest, humorous details about itself in the blog (Gordon, 2006). This was so successful that the blog was incorporated into the company's website and, as a result, the website's page impressions increased significantly from 240 to 1500 in the first month (Gordon, 2006).

Another challenge for SMEs who might wish to establish a blog to promote their online presence is deciding whether the blog should be incorporated into their website (assuming they have one) or be hosted by a third-party platform provided by such companies as Google, Technorati and BuzzMetrics (Goodfellow \& Graham, 2007). The advantage of the third-party platforms is that they 
offer SMEs technical support and value-added services for administering their blogs, such as data metrics, data mining, information filtering, and topic tagging (Goodfellow \& Graham, 2007).

These issues give rise to a number of research questions which can provide the impetus for future research in this area.

RQ18: To what extent can blog use by SMEs improve their ranking in search engine results and increase the online traffic to their website?

RQ19: How frequently should SMEs update blog content to promote their online presence effectively, and is this realistic for SMEs given their limited resources?

RQ20: To what extent do third-party platforms provide the tools needed so SMEs, with limited resources and skills, can administer blogs effectively?

RQ21: What technical skills do SME owner-managers or employees need to run blogs successfully? ("Success" would vary depending on what an SME aims to achieve.)

\section{DISCUSSION}

The preceding analysis of the literature on SMEs and blogs has determined that there are no clear answers at this stage as to whether blogs would be an effective marketing tool for SMEs. Based on the limited research in this area we argue that the suitability of blogs for SMEs will most likely depend on the specific internal and external contexts of an SME, and also on the marketing strategies and processes which the SMEs are using (if at all) or trying to achieve. These two broad perspectives of the future research agenda are important because, as we stated earlier, existing eBusiness research relating to SMEs has tended to treat eBusiness collectively rather than differentiating between the different business uses of tools like blogs (Parker \& Castleman, 2007), and to treat SMEs as a homogeneous group (see Castleman, 2004; Martin \& Matlay, 2001; Parker \& Castleman, 2007). This paper therefore makes a significant conceptual contribution because it demonstrates how eBusiness research can be reconceptualised to ensure that SME heterogeneity, and the specific business uses of an eBusiness technology, can become central to the research questions we pursue. In order to clarify how the various research questions from the previous section support SME heterogeneity, we have grouped the research questions in Figure 1 according to the different SME contexts.

Each research question comprising the research agenda outlined in the previous section and Figure 1 can be used as the basis for individual studies involving various research approaches. These approaches could include case studies, telephone/postal/email surveys, semi-structured interviews, action research studies, focus groups and possibly even experimental studies. For example:

- Exploratory interviews with SME owner-managers and case studies of SMEs (which could also include staff) would provide insights into the internal marketing and eBusiness capabilities they need so that they can use blogs effectively. This will provide an indication of the types of SMEs which could use blogs as a marketing tool. In addition, this exploratory research could also examine the types of marketing which SMEs use and find effective, and use this as a basis for investigating whether blogs can support these marketing approaches. These findings could then lead to structured survey studies (with larger and more generalisable sample sizes, and more specific variables and constructs) to examine these areas, and specific research hypotheses, in more depth. 


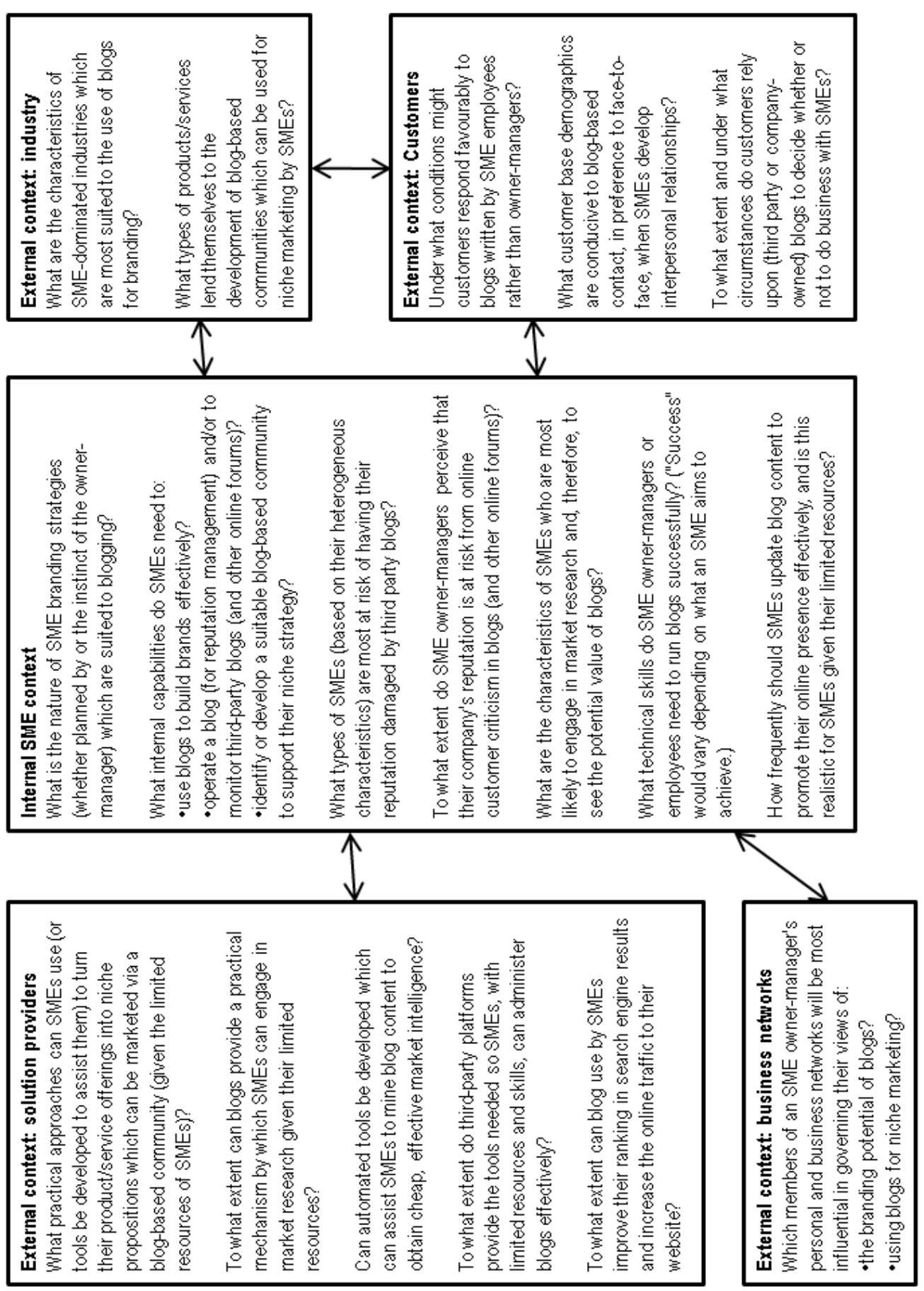

Figure 1: Contexts and Research Questions Relating to Blog use by SMEs 
- Action research and experimental studies could be conducted to determine how blog-based tools can be improved so that they address the heterogeneous needs of the SME sector. The outcomes of this research might in turn help eBusiness technology providers to offer solutions which are suitable to more types of SMEs and, consequently, will be more readily adopted. This might include exploring opportunities for automating marketing processes, such as market intelligence gathering, which are suited to SMEs with limited time and resources.

- Website content analysis research could be conducted to develop a greater understanding of the types of industries, products and services more suited to blogging. This will enable other researchers to target their SME-focused studies on particular industries in which SME take-up of blogging might be more likely or, if take-up is not occurring, to examine the idiosyncratic SME contexts within these industries which might help explain this slow up-take. This could also lead to industry-specific customer profile analyses (for example, using surveys of the customer base in a particular industry) to develop an understanding of their use of blogs. The results of this research could be provided to SMEs in the industry to determine whether it changes their perceptions of the role of blogs in their marketing endeavours.

- Social network analyses could be carried out to explore the personal and business networks in which SME owner-managers are embedded. This research could generate insights into the knowledge sharing dynamics within the networks to determine the best way to assist ownermanagers to learn about blogs and make informed choices about whether to use blogs for marketing purposes.

We can see from these examples of potential research projects arising from our research agenda that developing a "big picture" of the types of SMEs which can benefit from blogs for marketing will require a concerted effort by many in the eBusiness research community. As we stated at the start of the paper, this "big picture" concerning eBusiness adoption and use by SMEs is important because the literature in this area is quite fragmented (Parker \& Castleman, 2007). Our research agenda (and others which could be developed for other eBusiness technologies) might help researchers appreciate how their specific research projects fit into the broader scholarly pursuit of understanding the SME contexts in which the adoption of particular eBusiness tools makes sense.

More importantly, Parker and Castleman (2009) suggest that, as a research community, we need to reflect on and critique existing theory, or build new theory, based on our empirical research on SME adoption of eBusiness tools like blogs. Parker and Castleman propose an integrated theoretical framework which can provide the starting point for such critical reflection. Their framework is based on Rogers' (2003) Diffusion of Innovation Theory because it provides an overarching theory, and their framework incorporates complementary theories such as Social Network Theory and Resource-based Theory which help explain the social dynamics among SME owner-managers and their personal/business networks. The types of theoretical questions which, as a research community, we need to ask is whether these combinations of theories are adequate for explaining eBusiness adoption decisions by SME owner-managers, or whether our empirical findings suggest we need refinements to or even entirely new theories. We believe that our proposed research agenda, and the specific project ideas outlined above, will assist by providing the impetus for empirical research in which we can reflect upon and critique theory which takes into account the heterogeneous nature of SMEs and the eBusiness tools they can use. 


\section{CONCLUSION}

This paper has argued that there has been limited research which aims to determine the types of SMEs for which blogs could be a potential marketing tool, and has proposed a future research agenda which will help the eBusiness research community to address this gap in knowledge. More specifically, the paper has shown how a comprehensive research agenda can be formed which recognises that SMEs are heterogeneous and that eBusiness technologies must be viewed in terms of their business applications. In the context of this paper, the eBusiness technology was blogs and the business applications concerned looking at the specific marketing strategies and processes of SMEs. This is significant because existing eBusiness research relating to SMEs has tended to treat eBusiness collectively rather than focusing on specific business uses (Parker \& Castleman, 2007), and to treat SMEs as a homogeneous group (see Castleman, 2004; Martin \& Matlay, 2001; Parker \& Castleman, 2007).

While this paper has focused specifically on blogs, we also believe that a similar approach could be used to formulate future research agendas for other eBusiness technologies. If such agendas are developed which take SME and eBusiness technology heterogeneity into account, then as an eBusiness research community we are more likely to produce empirical findings which enable us to reflect more critically on the state of theory relating to SMEs, their heterogeneity and their eBusiness adoption/use. This is because researchers are more likely to see how their specific research projects fit within a "big picture" of scholarly endeavour, and start to question the underlying theories which contribute to our understanding of this area.

\section{REFERENCES}

Ahn, C., Lee, H.S., Park, M. \& Roh, S. (2007) "Project-based Knowledge Management System Using Blog", 24th International Symposium on Automation \& Robotics in Construction, Madras, India.

Ahonen, M. \& Syvänen, A. (2007) "How can electronic portfolios facilitate collaborative problemfinding in the innovation process?". http://beyondcreativity.blogs.com/mblog/files/iadis_mobile_learning_dublin_ahonen_syvnen _creativity_portfolios_final.pdf (accessed 19 June 2009).

Al-Qirim, N.A.Y. (2005) "An empirical investigation of an e-commerce adoption-capability model in small businesses in New Zealand", Electronic Markets, Vol 15 No 4, pp 418-437.

Alexander, C., Pearson, J.M. \& Crosby, L. (2003) "The transition to e-commerce: a case study of a rural-based travel agency", Journal of Internet Commerce, Vol 2 No 1, pp 49-63.

Ambler, T. (1992) Need-to-Know-Marketing: An Accessible A to Z Guide, Century Business, London.

Anderson, C. \& Mayfield, R. (2009) "Fortune 500 Business Blogging Wiki". http://www.socialtext.net/bizblogs/index.cgi (accessed 17 April 2009).

Arnold, D. (1992) The Handbook of Brand Management, Addison-Wesley, Reading, Massachusetts. 
Beck, R., Wigand, R.T. \& König, W. (2005) "The diffusion and efficient use of electronic commerce among small and medium-sized enterprises: an international three-industry survey", Electronic Markets, Vol 15 No 1, pp 38-52.

Beckinsale, M., Levy, M. \& Powell, P. (2006) "Exploring internet adoption drivers in SMEs", Electronic Markets, Vol 16 No 4, pp 361-370.

Brooks, G. (2006) "The risks and rewards of the branded blog", Marketing, 6 December, pp 44-46.

Brown, D.H. \& Lockett, N.J. (2004) "Potential of critical e-applications for engaging SMEs in ebusiness: a provider perspective", European Journal of Information Systems, Vol 13 No 1, pp 21-34.

Bughin, J. \& Manyika, J. (2007) "How businesses are using Web 2.0: A McKinsey Global Survey", The McKinsey Quarterly. http://www.finextra.com/Finextradownloads//featuredocs/hobu07.pdf (accessed 19 June 2009).

Burke, K. (2005) "The impact of firm size on Internet use in small businesses", Electronic Markets, Vol 15 No 2, pp 79-93.

Caldeira, M.M. \& Ward, J.M. (2003) "Using resource-based theory to interpret the successful adoption and use of information systems and technology in manufacturing small and medium-sized enterprises", European Journal of Information Systems, Vol 12 No 2, pp 127141.

Carmichael, J. \& Helwig, S. (2006) "Corporate Weblogging Best Practices: A guide for enterprises seeking to leverage corporate blogs". http://www.uwebc.org/opinionpapers/archives/docs/CorporateBlogging.pdf (accessed 19 June 2009).

Carter, B. (2006) "Blogs in Business", Marketing, 1 March, pp 35-36.

Castleman, T. (2004) "Small businesses as social formations: diverse rationalities in the context of e-business adoption", in: N.A.Y. Al-Qirim (ed.) Electronic Commerce in Small to MediumSized Enterprises: Frameworks, Issues and Implications, Idea Group Publishing, Hershey, Pennsylvania, pp 31-51.

Ching, H.L. \& Ellis, P. (2004) "Marketing in cyberspace: what factors drive e-commerce adoption?", Journal of Marketing Management, Vol 20 No 3/4, pp 409-429.

Chong, S. (2006) "An empirical study of factors that influence the extent of deployment of electronic commerce for small- and mediumsized enterprises in Australia", Journal of Theoretical and Applied Electronic Commerce Research, Vol 1 No 2, pp 45-57.

Cooke, M. (2006) "The importance of blogging", International Journal of Market Research, Vol 48 No 6, pp 645-646.

Cox, J.L., Martinez, E.R. \& Quinlan, K.B. (2008) "Blogs and the corporation: managing the risk, reaping the benefits", Journal of Business Strategy, Vol 29 No 3, pp 4-12.

de Guinea, A.O., Kelley, H. \& Hunter, M.G. (2005) "Information systems effectiveness in small businesses: extending a Singaporean model in Canada", Journal of Global Information Management, Vol 13 No 3, pp 55-79.

Deelmann, T. \& Loos, P. (2002) "Trust Economy: Aspects of Reputation and Trust Building for SMEs in eBusiness", 8th Americas Conference on Information Systems, 9-11 August, Dallas, Texas, USA, pp 2213-2221. 
DeFelice, A. (2006) "Let's review: A new web marketing tool". http://www.destinationcrm.com/Articles/ReadArticle.aspx?ArticleID=42416 (accessed 23 January 2008).

Del Aguila-Obra, A.R. \& Padilla-Meléndez, A. (2006) "Organizational factors affecting Internet technology adoption", Internet Research: Electronic Networking Applications and Policy, Vol 16 No 1, pp 94-110.

Dholakia, R.R. \& Kshetri, N. (2004) "Factors impacting the adoption of the internet among SMEs", Small Business Economics, Vol 23 No 4, pp 311-322.

Dwyer, P. (2007) "Building Trust with Corporate Blogs", 1st International Conference on Weblogs and Social Media, 26-28 March, Boulder, Colorado, USA.

Fillis, I., Johannson, U. \& Wagner, B. (2004) "Factors impacting on e-business adoption and development in the smaller firm", International Journal of Entrepreneurial Behaviour and Research, Vol 10 No 3, pp 178-191.

Galloway, L. \& Mochrie, R. (2005) "The use of ICT in rural firms: a policy-orientated literature review", Info, Vol 7 No 3, pp 33-46.

Gemino, A., Mackay, N. \& Reich, B.H. (2006) "Executive decisions about website adoption in small and medium-sized enterprises", Journal of Information Technology Management, Vol 17 No 1, pp 34-49.

Gibbs, S., Sequeira, J. \& White, M.M. (2007) "Social networks and technology adoption in small business", International Journal of Globalisation and Small Business, Vol 2 No 1, pp 66-87.

Goodfellow, T. \& Graham, S. (2007) "The blog as a high-impact institutional communication tool", The Electronic Library, Vol 25 No 4, pp 395-400.

Gordon, S. (2006) "Rise of the blog", IEE Review, Vol 52 No 3, pp 32-35.

Gray, R. (2006) "Wake up to digital danger", Marketing, 6 December, p 38.

Habermann, J. (2005) "Analysis of the usage and value of weblogs as a source of business news and information".

http://blog.jackvinson.com/files/Report_Analysis_of_the_usage_and_value_of_weblogs_Juli a_Habermann.pdf (accessed 19 June 2009).

Hamburg, I. (2008) "Introducing e-Learning 2.0 in SME: A Practical Guide". http://www.iatge.de/aktuell/veroeff/2008/hamburg02.pdf (accessed 19 June 2009).

Hamburg, I. \& Hall, T. (2008) "Informal learning and the use of Web 2.0 within SME training strategies", eLearning Papers, No 11, p 4.

Hanson, K. (2006) "Should the Boss be Blogging?", Strategic Communication Management, Vol 10 No 2, pp 6-7.

Harris, L., Rae, A. \& Grewal, S. (2008) "Out on the pull: how small firms are making themselves sexy with new online promotion techniques", International Journal of Technology Marketing, Vol 3 No 2, pp 153-168

Hewitt, H. (2005) Blog - Understanding the Information Reformation That's Changing Your World, Thomas Nelson, Nashville, Tennesse.

Holtz, S. (2005) "Using employee blogs on the intranet", Strategic Communication Management, Vol 9 No 5, p 3. 
Horton, J.L. (2003) "Marketing And Blogs: What Works". http://onlinepr.com/Holding/MarketingandBlogs-WhatWorks.pdf (accessed 19 June 2009).

James, T. (2008) "Five reasons why blogging makes sense for smaller businesses". http://www.bulletpoints.co.nz/five-reasons-why-blogging-makes-sense-for-smallerbusinesses/ (accessed 12 June 2009).

Jones, C., Hecker, R. \& Holland, P. (2003) "Small firm Internet adoption: opportunities forgone, a journey not begun", Journal of Small Business and Enterprise Development, Vol 10 No 3, pp 287-297.

Judge, R. (2007) "The Influence of Information Linkage on User Acceptance of a Knowledge Management System (KMS) in Small to Mid-size Enterprises (SME)", 40th Hawaii International Conference on System Sciences, 3-6 January, Hawaii, pp 194a-201a.

Khazanchi, D. (2005) "Information technology (IT) appropriateness: the contingency theory of "fit" and IT implementation in small and medium enterprises", Journal of Computer Information Systems, Vol 45 No 3, pp 88-95.

Kirkpatrick, D., Roth, D. \& Ryan, O. (2005) "Why There's No Escaping The Blog", Fortune, Vol 151 No 1, pp 44-50.

Kotler, P., Armstrong, G., Saunders, J. \& Wong, V. (1996) Principles of Marketing, Prentice-Hall, Englewood Cliffs, New Jersey, USA.

Lee, S., Hwang, T. \& Lee, H.H. (2006) "Corporate blogging strategies of the Fortune 500 companies", Management Decision, Vol 44 No 3, pp 316- 335.

Levenburg, N.M. (2005) "Does size matter? Small firms' use of e-business tools in the supply chain", Electronic Markets, Vol 15 No 2, pp 94-105.

MacGregor, R.C. \& Vrazalic, L. (2007) "Small business clusters and their role in prioritising barriers to e-commerce adoption: a study of two approaches to cluster development", International Journal of Electronic Marketing and Retailing, Vol 1 No 3, pp 236-259.

Martin, L.M. \& Matlay, H. (2001) "'Blanket'approaches to promoting ICT in small firms: some lessons from the DTI ladder adoption model in the UK", Internet Research: Electronic Networking Applications and Policy, Vol 11 No 5, pp 399-410.

Martin, L.M. \& Matlay, H. (2003) "Innovative use of the Internet in established small firms: the impact of knowledge management and organisational learning in accessing new opportunities", Qualitative Market Research: An International Journal, Vol 6 No 1, pp 18-26.

Nooteboom, B. (1994) "Innovation and diffusion in small firms: theory and evidence", Small Business Economics, Vol 6 No 5, pp 327-347.

O'Flaherty, N. (2008) "Corporate Blogging: Why New Zealand companies should blog". http://www.bulletpoints.co.nz/corporate-blogging-why-new-zealand-companies-should-blog/ (accessed 12 June 2009).

Parker, C.M. \& Castleman, T. (2007) "New directions for research on SME-eBusiness: insights from an analysis of journal articles from 2003 to 2006", Journal of Information Systems and Small Business, Vol 1 No 1-2, pp 21-40.

Parker, C.M. \& Castleman, T. (2009) "Small firm eBusiness adoption: a critical analysis of theory", Journal of Enterprise Information Management, Vol 22 No 1/2, pp 167-182. 
Resnick, P., Zeckhauser, R., Friedman, E. \& Kuwabara, K. (2000) "Reputation Systems", Communications of the ACM, Vol 43 No 12, pp 45-48.

Rogers, E.M. (2003) Diffusion of Innovations, 5th edition, Free Press, New York.

Schmidt, J. (2007) "Blogging Practices: An Analytical Framework", Journal of Computer-Mediated Communication, Vol 12 No 4, pp 1409-1427.

Schroth, C. \& Janner, T. (2007) "Web 2.0 and SOA: Converging Concepts Enabling the Internet of Services", IT Professional, Vol 9 No 3, May, pp 36-41.

Scoble, R. \& Israel, S. (2006) Naked Conversations: How Blogs are Changing the Way Businesses Talk with Customers, John Wiley, Hoboken, New Jersey, USA.

Sherman, E. \& Weinberger, D. (2006) "Out of Control", Advertising Age, Vol 77 No 14, pp 9-12.

Simmons, G.J., Armstrong, G.A. \& Durkin, M.G. (2008) "A conceptualization of the determinants of small business website adoption: setting the research agenda", International Small Business Journal, Vol 26 No 3, pp 351-389.

Simpson, M. \& Docherty, A.J. (2004) "E-commerce adoption support and advice for UK SMEs", Journal of Small Business and Enterprise Development, Vol 11 No 3, pp 315-328.

Singh, T., Veron-Jackson, L. \& Cullinane, J. (2008) "Blogging: A new play in your marketing game plan", Business Horizons, Vol 51 No 4, pp 281-292.

Stansfield, M. \& Grant, K. (2003) "An investigation into issues influencing the use of the Internet and electronic commerce among small-medium sized enterprises", Journal of Electronic Commerce Research, Vol 4 No 1, pp 15-33.

Taylor, D. (2005) "Debunking the myth of Kryptonite Locks and the Blogosphere". http://www.intuitive.com/blog/debunking_the_myth_of_kryptonite_locks_and_the_blogosph ere.html (accessed 19 June 2009).

Technorati (2008) "State of the Blogosphere: 2008". http://technorati.com/blogging/state-of-theblogosphere/ (accessed 19 June 2009).

Tsao, H.-Y., Lin, K.H.C. \& Lin, C. (2004) "An investigation of critical success factors in the adoption of B2BEC by Taiwanese companies", Journal of American Academy of Business, Cambridge, Vol 5 No 1/2, pp 198-202.

Tucker, D. \& Lafferty, A. (2004) "Implementing electronic commerce in SMEs: processes and barriers", Journal of Electronic Commerce in Organizations, Vol 2 No 4, pp 20-29.

Universal McCann (2008) "Universal McCann: Power To The People - Wave3.". http://www.universalmccann.com/Assets/2413\%20-

\%20Wave\%203\%20complete\%20document\%20AW\%203_20080418124523.pdf (accessed 19 June 2009).

van der Wolf, M. (2007) "The Business Value of Blogging". http://www.scribd.com/doc/39802/LEWIS-PR-Business-value-of-blogging (accessed 19 June 2009).

Wagner, B.A., Fillis, I. \& Johansson, U. (2003) "E-business and e-supply strategy in small and medium sized businesses (SMEs)", Supply Chain Management: An International Journal, Vol 8 No 4, pp 343-354.

Walmsley, A. (2006) "Clumsy attempt at being compelling", Marketing, 25 October, p 13. 
Woffington, J. (2006) "Outlook 2006: CPG marketers find Web is place to build relationships". http://www.dmnews.com/Outlook-2006-CPG-Marketers-Find-Web-Is-Place-to-BuildRelationships/article/90304/ (accessed 7 August 2007).

Wright, J. (2006) Blog Marketing - The Revolutionary New Way To Increase Sales, Build Your Brand and Get Exceptional Results, McGraw-Hill, New York.

Wymer, S. \& Regan, E. (2005) "Factors influencing e-commerce adoption and use by small and medium businesses", Electronic Markets, Vol 15 No 4, pp 438-453.

Xu, M., Rohatgi, R. \& Duan, Y. (2007) "E-business adoption in SMEs: some preliminary findings from electronic components industry", International Journal of E-Business Research, Vol 3 No 1, pp 74-90.

Young, G.O., Daley, E., Lo, H. \& Lawson, A. (2007) "Efficiency Gains and Competitive Pressures Drive Enterprise Web 2.0 Adoption", Forrester Research. http://www.forrester.com/Research/Document/Excerpt/0,7211,41794,00.html.

Zheng, J., Caldwell, N.D., Harland, C.M., Powell, P., Woerndl, M. \& Xu, S. (2004) "Small firms and e-business: cautiousness, contingency and cost-benefit", Journal of Purchasing and Supply Management, Vol 10 No 1, pp 27-39.

Zontanos, G. \& Anderson, A.R. (2004) "Relationships, marketing and small business: an exploration of links in theory and practice", Qualitative Market Research: An International Journal, Vol 7 No 3, pp 228-236. 